REVESCO. Revista de Estudios Cooperativos

ISSN: $1885-8031$

\title{
Las sociedades cooperativas de España: empresas creadoras de empleo. Una especial referencia a Andalucía
}

\author{
Macarena Pérez-Suárez ${ }^{1}$ e Isadora Sánchez-Torné ${ }^{2}$ \\ Recibido: 18 de enero de 2019 / Aceptado: 6 de julio de 2020 / Publicado: 30 de noviembre de 2020
}

\begin{abstract}
Resumen. La interacción entre el empleo y el ciclo económico permite observar el comportamiento de las cooperativas en las comunidades autónomas de España. El análisis tuvo como objetivo determinar el potencial generador de empleo de las cooperativas españolas, particularizando en Andalucía. Se utilizó una metodología inductiva mediante un análisis estadístico descriptivo y un análisis shift-share. Los resultados constataron que, respecto a España, Andalucía se destaca significativamente en parte de las variables observadas. Para el periodo 2005-2016 aumentó en mayor porcentaje el número de personas empleadas en las cooperativas de la región que en el conjunto del país. En particular, durante el periodo de crisis (2008-2015), las cooperativas incrementaron el número de personas ocupadas poniendo de manifiesto la mayor capacidad de generar empleo que el resto de las formas jurídicas de la Economía Social.
\end{abstract}

Palabras clave: Análisis shift-share; Ciclo Económico; Cooperativas; Empleo.

Claves Econlit: J54; P13; R10.

\section{[en] Co-operatives societies in Spain: job-creating firms. a special reference to Andalusia}

\begin{abstract}
The interaction between employment and the economic cycle makes it possible to observe the behavior of cooperatives in Spain's regions. The aim of the analysis was to determine the job creation potential of Spanish cooperatives, particularly in Andalusia. An inductive methodology was used through a descriptive statistical analysis and a shift-share analysis. The results showed that, with respect to Spain, Andalusia stands out significantly in some of the variables observed. For the period 2005-2016, the number of people employed in co-operatives in the region increased by a greater percentage than in the country as a whole. In particular, during the period of crisis (2008-2015), cooperatives increased the number of people employed, demonstrating their greater capacity to generate employment than the other legal forms of the Social Economy.
\end{abstract}

Keywords: Co-operatives; Economic Cycle; Employment; Shift Share Analysis.

Sumario. 1. Introducción. 2. Revisión de la Literatura. 3. Metodología. 4. Resultados. 5. Conclusiones. 6. Referencias bibliográficas.

Cómo citar. Pérez-Suárez, M.; Sánchez-Torné, I. (2020) Las sociedades cooperativas de España: empresas creadoras de empleo. Una especial referencia a Andalucía. REVESCO. Revista de Estudios Cooperativos, vol. $136, \quad$ e71860. https://dx.doi.org/10.5209/reve.71860.

\section{Introducción}

En España, a nivel normativo, se reconoce como Economía Social "al conjunto de las actividades económicas y empresariales, que en el ámbito privado llevan a cabo aquellas entidades que, de conformidad con los principios recogidos en el artículo cuatro, persiguen bien el interés colectivo de sus integrantes, bien el interés general económico o social, o ambos"3. Por consiguiente, desde el ámbito académico se señala que la Economía Social (ES) es una economía real basada en valores democráticos e igualitarios, decididamente, una forma propia de generar empleo, renta y riqueza (Pérez y Carrillo, 2000; Sanchis y Campos, 2005; Monzón y Chaves, 2012; Calderón y Calderón, 2012b).

\footnotetext{
Universidad de Sevilla, España.

Dirección de correo electrónico: mperez32@us.es.

2 Universidad de Sevilla, España.

Dirección de correo electrónico: isanchez6@us.es.

Artículo 2, de la Ley 5/2011, de 29 de marzo, de Economía Social.
} 
La relevancia económica de la Economía Social en España ${ }^{4}$ reside en representar más del $12 \%$ del empleo nacional con 2.177.256 empleos directos e indirectos ${ }^{5}$ (CEPES, 2019), pues le precede desde 2010 una tendencia positiva en la evolución del empleo remunerado (Monzón y Chaves, 2017:78). Específicamente, en el año 2018 la ES española aglutinaba a 42.140 empresas de las cuales 19.954 eran cooperativas y 8.725 sociedades laborales ${ }^{6}$, una regularidad nacional registrada desde 2017 y, la entrada en vigor del Programa de Fomento de la Economía Social y el Programa Operativo de Inclusión Social y Economía Social para el período 2014-2020, cofinanciado por el Fondo Social Europeo7. Según Martínez, Sabín, Álvaro, Gallero y Salsón (2019:13), el total de empleo y el total de sociedades "equivalen al 10-12\% del PIB" y a una vinculación estimada del $42,8 \%$ de la población española. Se añade que, a nivel regional, en la última década se han desarrollado buenas prácticas como en Andalucía y Murcia, pues al sur de España se han logrado las mayores tasas de desarrollo de cooperativas del país (Chaves y Demoustier, 2013).

Dentro de la Economía Social, la investigación afronta el cooperativismo por dos razones, una cualitativa y otra cuantitativa. Por una parte, se halla la defensa de las limitadas estadísticas existentes sobre las tipologías jurídicas tradicionales (cooperativas ${ }^{8}$ y mutualidades). Taxativamente, las cooperativas españolas, suponen alrededor de "7,3 millones de miembros, generan 290.000 empleos y 61.000 millones de euros, destacando los sectores de la agricultura (3.844 cooperativas con 99.000 personas empleadas) y la industria, los servicios y el ámbito social (17.000 cooperativas y 23.000 personas empleadas)" (Martínez et al., 2019:10-14).

Además, se presta atención a la comunidad autónoma de Andalucía, por un cooperativismo significativo, "ya que el 19\% de las cooperativas y el 18\% del empleo que éstas generan a nivel nacional se encuentran en Andalucía. A ello hay que añadir que existe un reconocimiento institucional consolidado de estas organizaciones que se evidencia por las leyes reguladoras de éstas, los Pactos Andaluces por la Economía Social o los diferentes programas de apoyo a sus organizaciones" (Valiente, 2019:55). En consecuencia, se pretende afianzar si las cooperativas andaluzas son organizaciones de ES representativas a nivel territorial (Valiente, 2019:69) e identificar la generación de empleo, pues adquiere interés para las políticas específicas territoriales al tratarse de sociedades sociales (Pérez y Valiente, 2019:122).

A finales del año 2016 existían en Andalucía 3.994 cooperativas que daban empleo a 57.864 personas, si se actualiza la afirmación, a finales de 2019 concurrían en Andalucía 3.852 cooperativas que daban empleo a 60.989 personas $^{9}$. Esta existencia significativa, se convierte en una oportunidad para determinar la resistencia del empleo ante las variaciones del ciclo económico.

En este contexto, se observa la relación entre las Cooperativas, organizaciones de la ES, y el empleo a la luz de las características y especificidades territoriales que pueden influir en su evolución y comportamiento. El diagnóstico abarca todas las Comunidades Autónomas de España para mostrar el potencial generador de empleo de la sociedad cooperativa. La referencia al ámbito nacional y regional se basa en datos estadísticos correspondientes a al intervalo temporal 2005-2016. Basándose en una metodología inductiva se realiza un análisis estadístico descriptivo y un análisis shift-share que toma en consideración cinco variables ${ }^{10}$ : cooperativas constituidas, cooperativas inscritas, personas trabajadoras en cooperativas inscritas, total de empresas inscritas en la seguridad social, y personas trabajadoras del total de empresas inscritas en la seguridad social. Finalmente, el presente trabajo supone un valor añadido a trabajos previos citados sobre las ventajas que suponen las sociedades cooperativas desde la perspectiva del empleo y la organización territorial (Pérez y Valiente, 2019:125).

El artículo se encuentra estructurado en cinco apartados. Se inicia con una revisión de los trabajos recientes sobre la temática del empleo en la ES, seguidamente, se indica la metodología del análisis y se abordan los resultados alcanzados en la caracterización de las variables observadas del ciclo económico y su manifestación. Esos resultados permiten exponer las principales averiguaciones de la investigación.

\footnotetext{
Según el Informe Mundial Cooperativas y Empleo por la CICOPA (Organización Internacional Cooperativa en la Industria y los Servicios, 2014): "al menos la Economía Social ocupa a 250 millones de personas en todo el mundo, lo cual corresponde al 8,73\% de la población ocupada mundial. De ellos 26,4 millones trabajan en cooperativas. El empleo dentro del ámbito de las cooperativas, a saber, los productos individuales o Pymes en los sectores de la agricultura, la pesca, la industria, la artesanía, el transporte etc., superan 223,6 millones de personas, pertenecientes la gran mayoría de ellos al sector agrícola."

Fuente: Cepes España en https://www.cepes.es/social/estadisticas\&e=personas_relacionadas_es.

Fuente: Cepes España en https://www.cepes.es/social/estadisticas\&e=entidades_evolucion.

Fuente: https://fse.cepes.es/.

Estas organizaciones son definidas por la Alianza Cooperativa Internacional (ACI) como "asociaciones de personas que se unen voluntariamente para satisfacer sus necesidades y aspiraciones económicas, sociales y culturales comunes, por medio de una empresa de propiedad conjunta gestionada democráticamente (...) hay que añadir que basan su funcionamiento en una serie de principios y valores de actuación" (Pérez y Valiente, 2019:123).

9 Fuente: Ministerio de Trabajo y Economía Social. Ministerio de Inclusión, Seguridad Social y Migraciones. Estadísticos disponibles en http://www.mitramiss.gob.es/es/sec trabajo/autonomos/economia-social/estadisticas/sociedades-alta-ssocial/2019/indice.htm.

10 Ver definición en Tabla 1.
} 


\section{Revisión de la Literatura}

El contenido del artículo se sustenta en los tópicos de estudio «cooperativas» y «empleo», según DíazFoncea y Marcuello-Servós (2010) al mostrar el impacto del ciclo económico sobre el empleo de las sociedades cooperativas, pues son las entidades más dinámicas y cuantitativamente relevantes de la ES española. El interés por la medición cuantitativa del rol de la ES en el ámbito territorial se refleja también en diversas aportaciones nacionales (Grávalos y Pomares, 2001; Cubedo, 2006; Chaves y Monzón, 2007; Cuadrado-Serrán y Ciruela-Lorenzo 2014; Pérez y Valiente, 2017). Esos estudios consideran la relación del empleo de las cooperativas y el ciclo económico, desde el conjunto de la economía o las regiones (ClementeLópez et al., 2014) a los cambios en el escenario político y la estructura productiva (Román-Cervantes, 2014). El Cuadro 1 presenta una síntesis de las referencias examinadas.

\section{Cuadro. 1. Revisión de la Literatura.}

\begin{tabular}{|c|c|c|}
\hline Período & Autorías & Principales Premisas \\
\hline 2010 & $\begin{array}{l}\text { Díaz-Foncea y } \\
\text { Marcuello-Servós }\end{array}$ & $\begin{array}{l}\text { El empleo en las cooperativas adquiere un comportamiento procíclico (el empleo } \\
\text { cooperativo < sensible a la fase del ciclo económico que el empleo total de la } \\
\text { economía nacional). En fases expansivas, las cooperativas se muestran menos } \\
\text { dinámicas en la generación de empleo, mientras que en períodos recesivos, la } \\
\text { destrucción de empleo es mucho menor. }\end{array}$ \\
\hline 2010 & Melián y Campos & $\begin{array}{l}\text { Las empresas de ES han demostrado ser estratégicas en el desarrollo local con un } \\
\text { importante papel como entidades creadoras de empleo vinculadas a los territorios } \\
\text { de origen. }\end{array}$ \\
\hline $2012 a$ & $\begin{array}{l}\text { Calderón y } \\
\text { Calderón }\end{array}$ & $\begin{array}{l}\text { Las empresas de ES crean empleo en el macro-contexto de destrucción en } \\
\text { España. }\end{array}$ \\
\hline 2013 & $\begin{array}{l}\text { Castro, Santero, } \\
\text { Martínez y Guilló }\end{array}$ & $\begin{array}{l}\text { La ES aporta de forma directa a la actividad económica, al empleo en España y } \\
\text { al incremento de la cohesión social. }\end{array}$ \\
\hline 2014 & $\begin{array}{l}\text { Clemente-López } \\
\text { et al. }\end{array}$ & $\begin{array}{l}\text { En período de crisis, las cooperativas mantienen el empleo junto a una mayor } \\
\text { creación de empresas. }\end{array}$ \\
\hline 2014 & $\begin{array}{l}\text { Cuadrado-Serrán } \\
\text { y Ciruela- } \\
\text { Lorenzo }\end{array}$ & $\begin{array}{l}\text { El empleo en la ES resistió la primera fase de la crisis (2008-2010) aunque no de } \\
\text { igual modo en los años sucesivos, se registran pérdidas netas de empleo. }\end{array}$ \\
\hline 2014 & Román-Cervantes & $\begin{array}{l}\text { Las cooperativas ascienden en la etapa de expansión económica (las cooperativas } \\
\text { industriales y las cooperativas trabajo asociado). Sin embargo, en las etapas de } \\
\text { exiguo crecimiento del PIB, el conjunto de cooperativas alcanza un mayor } \\
\text { dinamismo, reconociendo un perfil anticíclico. }\end{array}$ \\
\hline 2015 & $\begin{array}{l}\text { Fuentes-Saguar y } \\
\text { Mainar-Causapé }\end{array}$ & $\begin{array}{l}\text { Las empresas de ES poseen una capacidad propia para la creación de empleo } \\
\text { superior al resto de empresas nacionales, especialmente en el tercer sector. }\end{array}$ \\
\hline 2015 & $\begin{array}{l}\text { Sala-Ríos, } \\
\text { Torres-Solé, y } \\
\text { Farré-Perdiguer }\end{array}$ & $\begin{array}{l}\text { La crisis económica ha producido cambios en el empleo de las cooperativas, en } \\
\text { su comportamiento cíclico relativamente divergente al del ciclo económico y al } \\
\text { del empleo total, así, estas sociedades se muestran sensibles al ciclo económico y } \\
\text { su empleo ha disminuido su resistencia. }\end{array}$ \\
\hline 2017 & Blanco-Canto & $\begin{array}{l}\text { Las cooperativas tienen capacidad para crear y mantener el empleo en etapas de } \\
\text { recesión económica, como resultado de su peculiar gestión empresarial y elevada } \\
\text { adaptabilidad a los cambios locales. }\end{array}$ \\
\hline 2017 & Pérez y Valiente & $\begin{array}{l}\text { Estudios internacionales comprueban que la ES, en general y, las cooperativas en } \\
\text { particular, tienen una mayor resistencia a la destrucción del empleo en una fase } \\
\text { de recesión económica, llegando a mostrar un comportamiento contracíclico. }\end{array}$ \\
\hline 2019 & Valiente & $\begin{array}{l}\text { El cooperativismo podría estar suponiendo una oportunidad de empleo para las } \\
\text { mujeres y jóvenes en los territorios rurales de Andalucía. }\end{array}$ \\
\hline
\end{tabular}

Fuente: Elaboración Propia.

En el tratamiento de los tópicos «cooperativas» y «empleo» las referencias precedentes indican el interés temático, que en parte se debe al avance de las investigaciones sobre el papel de la ES y a la atención otorgada por varias instituciones académicas y de la sociedad civil que orientan recursos a tal fin. Se hallan mayores referencias al tema durante el periodo de crisis (2008-2015) y en el inicio de la recuperación, en comparación con el periodo pre-crisis. No obstante, los trabajos empíricos en los últimos diez años son escasos y limitados, por esta razón, se requiere un mayor conocimiento territorial sobre la ES desde una perspectiva socioeconómica e impacto laboral. 
En general, los estudios presentan evidencias sobre el peso del empleo de la ES en el empleo total, el grado de estabilidad y la evolución salarial, focalizando, en algunos casos, el segmento de las cooperativas (Castro, Santero, Martínez y Guilló, 2013). Sin embargo, concentrarse en un análisis del impacto directo en términos de actividad económica y empleo generado resulta insuficiente en una situación de crisis estructural. Los análisis que reconozcan la condición anticíclica de este tipo de empresas pueden impulsar la investigación hacia series temporales que puedan fortalecer el trabajo empírico de los últimos veinte años.

\section{Metodología}

En base a la literatura consultada, se realiza un estudio comparativo del sector cooperativo de España y sus comunidades autónomas, donde se observa la notoriedad de Andalucía. Un estudio que parte de una condición: en un período de recesión, la destrucción de empleos tiende a ser inferior en las cooperativas que, en el resto de las empresas mercantiles, y, por consiguiente, evidencia un comportamiento "amortiguador" de estas sociedades durante un periodo de crisis económica. Esta tendencia difiere a nivel territorial, ya que la generación de empleo refleja la no correlación regional y supraterritorial.

Al igual que otras autorías, se abordó una comparación de las sociedades cooperativas con las empresas mercantiles (Pérez y Valiente, 2019; Valiente, 2019). Para el análisis se seleccionaron las personas trabajadoras en cooperativas inscritas y las personas trabajadoras en el total de empresas inscritas en la Seguridad Social. Su definición, unidad de medidas y acotación temporal se describen en la Tabla 1. Las fuentes del análisis provienen de las estadísticas elaboradas por el Ministerio de Empleo y Seguridad Social ${ }^{11}$ y la Consejería de Economía y Conocimiento ${ }^{12}$.

Tabla. 1. Descripción de las variables, periodo utilizado y unidad de medida.

\begin{tabular}{|c|c|c|c|}
\hline \multicolumn{1}{|c|}{ Variable } & Definición & Periodo & Unidad de medida \\
\hline $\begin{array}{l}\text { Personas trabajadoras en } \\
\text { las cooperativas inscritas. }\end{array}$ & $\begin{array}{l}\text { Número de personas que trabajan en } \\
\text { una cooperativa. }\end{array}$ & $2005-2016$ & $\begin{array}{c}\text { Número de } \\
\text { trabajadoras-es. }\end{array}$ \\
\hline $\begin{array}{l}\text { Personas trabajadoras en el } \\
\text { total de empresas inscritas. }\end{array}$ & $\begin{array}{l}\text { Número de profesionales trabajadores } \\
\text { inscritos en la Seguridad Social. }\end{array}$ & $2005-2016$ & $\begin{array}{c}\text { Trabajadoras-es en } \\
\text { miles. }\end{array}$ \\
\hline
\end{tabular}

Fuente: Elaboración Propia a partir de la información de la Dirección General de la Economía Social del Trabajo Autónomo y de la Responsabilidad Social de las Empresas.

En las cuatro últimas variables, se tomaron como referencia cuatro periodos de estudio:

- 2005-2016: años en los que se dispone información,

- 2005-2007: periodo pre-crisis,

- 2008-2015: periodo de crisis,

- 2015 -2016: inicio de la recuperación.

Se realizó la elección del año 2008 por ser el inicio de la crisis económica y financiera (UE, 2008). A partir de los datos disponibles, se establece el año 2016 como principio de la recuperación, pues se observa una tasa de variación positiva entre los años 2015/16 tanto en el volumen de empleo como en número de empresas.

Para conocer la evolución de las variables objeto de estudio y determinar el potencial generador de empleo de las cooperativas, se calcularon y contrastaron las tasas de variación interanual y por periodos. La fórmula de la tasa de variación es la siguiente:

$\mathrm{Kca}^{t}=\frac{\left(X_{t}-X_{t-1}\right)}{X_{t-1}}$

Dónde:

$X_{t}$ : Número de trabajadores/número de empresas en el año $t$

$X_{t-1}$ : Número de trabajadores/número de empresas en año $t_{-1}$

11 Dirección General del Trabajo Autónomo, de la Economía Social y de la Responsabilidad Social de las Empresas, del Ministerio de Empleo y Seguridad Social (MEYSS). Datos disponibles en el momento de elaboración del trabajo.

12 Dirección General de Economía Social de la Consejería de Economía y Conocimiento. Datos disponibles en el momento de elaboración del trabajo. 
Para detectar el impacto en España del empleo en las cooperativas de las diferentes comunidades autónomas se utilizó la técnica shift-share (análisis de los desplazamientos) con el objetivo de descomponer el crecimiento del número de empleos en cooperativas en tres efectos distintos: nacional, dinámico y competitivo, y así, determinar a qué tipo de efecto se deben las variaciones de crecimiento en el empleo en cooperativas andaluzas. Concretamente, esta técnica de análisis regional es utilizada para conocer la evolución de una variable económica en un territorio teniendo como referencia un marco geográfico superior (Pérez-Suárez, 2016) ${ }^{13}$. Se trata de un análisis utilizado en investigaciones sobre comercio exterior (Gutiérrez, Morán, Belda, Sánchez-Torné y Pérez-Suárez, 2014; Ruiz, Peña y Jiménez, 2014; Belda y PérezSuárez, 2018) aunque también se utiliza para considerar la variable de empleo (Mayor-Fernández, LópezMenéndez y Pérez-Suárez, 2005; Albuquerque y Ferreira, 2015; Blanco-Canto, 2017; Rendón, Andrés y Mejía, 2019). El análisis Shift-share permite obtener conclusiones sobre los cambios sucedidos en regiones (en nuestro caso son comunidades autónomas) indicando si estos derivan de la tendencia general del territorio al que pertenece (en nuestro caso es España) o, por el contrario, se produce una tendencia particular de la región (Cieślak, Pawlewicz y Pawlewicz, 2019).

La técnica shift-share considera cuatro efectos distintos: total, nacional, competitivo y dinámico. En el caso de esta investigación, los datos empleados para su cálculo son el número de personas empleadas en las cooperativas. A continuación, se procede a explicar cada uno de ellos:

\section{Efecto Total: $\mathrm{Xca}^{t *} \mathrm{Kca}^{t}$}

El efecto nacional recoge el crecimiento o reducción que ha experimentado el número de personas trabajadoras de cooperativas en las comunidades autónomas si su tasa de crecimiento hubiera sido la media nacional. Determina qué parte de la variación es debida a la propia inercia estatal.

Efecto Nacional: $\mathrm{Xca}^{t} * \mathrm{Ke}^{t}$

El efecto competitivo cuantifica la influencia que tiene el comportamiento específico de las personas trabajadoras de las cooperativas en las comunidades autónomas frente a cómo evolucionan las cooperativas en España.

Efecto Competitivo: $X c a^{t} *\left(K_{c a}{ }^{t}-K c e^{t}\right)$

El efecto dinámico representa qué parte del diferencial respecto de la tasa de crecimiento nacional es debida a las cooperativas a nivel español.

Efecto Dinámico: $X c a^{t} *\left(K c e^{t}-K e^{t}\right)$

Dónde:

$\mathrm{Xca}^{t}$ : Número de empleos en las cooperativas comunidades autónomas en el año $\mathrm{t}$

$\mathrm{Kca}^{t}$ : Tasa de variación del número de personas trabajadoras en cooperativas comunidades autónomas entre el año $t$ y $t_{-1}$

$\mathrm{Ke}^{t}$ : Tasa de crecimiento del número de personas trabajadoras del total de empresas inscritas en la Seguridad Social en España entre el año $\mathrm{t}_{\mathrm{t}} \mathrm{t}_{1}$

$\mathrm{Kce}^{t}$ : tasa de crecimiento del número de personas trabajadoras en cooperativas españolas entre el año $t$ $\mathrm{yt}_{-1}$

Quedando la fórmula final de la siguiente forma: $\mathrm{Xca}^{t *} \mathrm{Kca}^{t}=\left(\mathrm{Xca}^{t} * \mathrm{Ke}^{t}\right)+\mathrm{Xca}^{t} *\left(\mathrm{Kca}^{t}-\mathrm{Kce}^{t}\right)+$ $\mathrm{Xca}^{t *}\left(\mathrm{Kce}^{t}-\mathrm{Ke}^{t}\right)$.

\section{Resultados}

\subsection{Evolución del Número de Personas Trabajadoras en empresas y en cooperativas inscritas}

En este apartado se estudia la evolución del número de personas trabajadoras en sociedades cooperativas en España y sus comunidades autónomas entre 2005 y 2016, junto a la comparación de la tasa de variación del número de personas empleadas en las cooperativas en las diferentes regiones nacionales.

En la Tabla 3 y Tabla 4, se observa que el número de personas trabajadoras de cooperativas entre 2005 y 2016 en España y las comunidades autónomas. De forma desagregada, se observan variaciones en los tres periodos entre 2005 y 2016 :

13 Fuente: Tesis Doctoral "El Proceso de Internacionalización de las empresas de Economía Social de Andalucía". Disponible en https://idus.us.es/xmlui/handle/11441/39173. 
Precrisis (2005-2007): el empleo aumentó, especialmente, en las cooperativas del País Vasco $(9,15 \%)$, Navarra $(7,15 \%)$, Comunidad de Madrid $(10,06 \%)$ y Baleares $(11,31 \%)$. Se redujo con mayor cuantía en La Rioja $(-16,44 \%)$ y Canarias $(-7,78 \%)$.

Crisis (2008-2015): el volumen de personas contratadas en cooperativas descendió un 6,45\% en España, mientras que Andalucía fue la segunda comunidad autónoma con mayor crecimiento en el número de personas empleadas en cooperativas, precedida por Navarra $(8,68 \%)$ y seguida por País Vasco $(6,64 \%)$. Por otro lado, destaca Baleares $(-46,61 \%)$ y La Rioja $(-30,75 \%)$ como las regiones con mayor destrucción de empleo en cooperativas.

En vía de recuperación (2015-2016): la tasa de variación fue positiva en la mayoría de las regiones y en España (4,66\%). Se precisa señalar que tres regiones disponen de un crecimiento más elevado: la Comunidad Valenciana (11,36\%), País Vasco (5,38\%) y Navarra (5,89\%). Persiste la reducción de personas contratadas en cooperativas en Asturias, Cantabria, Extremadura y La Rioja.

Por último, las Tablas 2, 3 y 4 benefician realizar una comparación entre la evolución del número de personas empleadas en cooperativas españolas y sus comunidades autónomas respecto al número de personas trabajadoras del total de empresas. Se observa que las regiones manifiestan cuatro tipos de comportamiento que se repiten en los periodos analizados, los cuales de detallan a continuación en segundo lugar.

Entre 2005 y 2016 se evidencia que hay regiones donde se ha producido una menor destrucción de empleo en el total de empresas: Aragón, Baleares, Canarias, Cantabria, Castilla La Mancha, Castilla y León, Cataluña, Extremadura, La Rioja, Ceuta y Melilla. Además, se comprueba una menor destrucción de empleo en las cooperativas de la Comunidad Valenciana y Galicia. Por otro lado, se registra una mayor creación de empleo en total de empresas (Murcia) y en las cooperativas de las regiones de Comunidad de Madrid, Navarra, País Vasco y Andalucía.

De forma disociada, se observan variaciones en los tres periodos:

En el periodo Precrisis (2005-2007), se encuentran dos tendencias:

- Las regiones donde se ha producido una mayor creación de empleo en total de empresas: España, Andalucía, Aragón, Asturias, Canarias, Cantabria, Castilla La Mancha, Castilla y León, Cataluña, Comunidad Valenciana, Extremadura, Galicia, Murcia, Navarra, La Rioja, Ceuta y Melilla.

- Las regiones donde se ha producido una mayor creación de empleo en cooperativas: Baleares, Comunidad de Madrid y País Vasco.

Durante el periodo de Crisis (2008-2015), se registra que:

- Siete regiones ocasionan una menor destrucción de empleo en el total de empresas, entre ellas, están Aragón, Asturias, Baleares, Canarias, Castilla y León. Por el contrario, en Murcia se produce una mayor creación de empleo en total de empresas.

- Cinco regiones donde se ha producido una mayor creación de empleo en cooperativas: Andalucía, Navarra, País Vasco, Ceuta y Melilla. En contrapisón, cinco regiones donde se ha producido una menor destrucción de empleo en cooperativas: Castilla La Mancha, Cataluña, Extremadura, Galicia y la Comunidad de Madrid.

En vía de recuperación (2015-2016), se manifiestan dos tipos de tendencias:

- Catorce regiones donde se ha originado una mayor creación de empleo en total de empresas: Andalucía, Aragón, Asturias, Baleares, Canarias, Cantabria, Castilla La Mancha, Castilla y León, Extremadura, Galicia, Comunidad de Madrid, La Rioja, Ceuta y Melilla.

- Cinco regiones donde se ha producido una mayor creación de empleo en cooperativas: Cataluña, Comunidad Valenciana, Murcia, Navarra y País Vasco. 
Tabla. 2. Número de personas trabajadoras en el Total Empresas Inscritas (en miles).

\begin{tabular}{|c|c|c|c|c|c|c|c|c|c|c|c|c|}
\hline $\begin{array}{c}\text { COMUNIDADES } \\
\text { AUTÓNOMAS }\end{array}$ & 2005 & 2006 & 2007 & 2008 & 2009 & 2010 & 2011 & 2012 & 2013 & 2014 & 2015 & 2016 \\
\hline ESPAÑA & $13.716,3$ & $14.347,8$ & $14.728,0$ & $13.827,2$ & $13.196,9$ & $13.555,8$ & $13.197,3$ & $12.497,1$ & $11.510,6$ & 11.762 & 12.306 & 12.832 \\
\hline ANDALUCÍA & $1.950,7$ & $2.062,6$ & $2.111,0$ & $1.904,5$ & $1.818,8$ & $2.088,6$ & $2.054,3$ & 1892,229 & $1.798,9$ & $1.782,3$ & $1.906,6$ & $1.998,7$ \\
\hline ARAGÓN & 413,2 & 437,4 & 456,1 & 430,1 & 413,9 & 410,5 & 398,1 & 381,694 & 341,3 & 348,2 & 360,8 & 374,0 \\
\hline ASTURIAS & 286,7 & 300,1 & 310,9 & 299,8 & 292,5 & 288,5 & 278,3 & 260,058 & 234,6 & 237,4 & 242,5 & 249,2 \\
\hline BALEARES & 288,2 & 301,8 & 311,4 & 290,6 & 273,7 & 270,7 & 259,0 & 250,267 & 231,6 & 242,7 & 258,3 & 276,5 \\
\hline CANARIAS & 625,5 & 652,1 & 656,1 & 600,0 & 561,9 & 570,6 & 558,3 & 537,02 & 501,4 & 520,8 & 544,6 & 578,8 \\
\hline CANTABRIA & 159,7 & 168,9 & 175,3 & 166,0 & 160,5 & 159,5 & 154,5 & 146,185 & 131,1 & 134,5 & 138,4 & 143,7 \\
\hline $\begin{array}{l}\text { CASTILLA Y } \\
\text { LEÓN }\end{array}$ & 668,5 & 700,0 & 727,1 & 697,4 & 680,8 & 674,0 & 659,3 & 618,03 & 552,2 & 561,9 & 582,5 & 599,9 \\
\hline $\begin{array}{l}\text { CASTILLA-LA } \\
\text { MANCHA }\end{array}$ & 495,9 & 530,2 & 562,3 & 519,5 & 499,7 & 511,8 & 484,3 & 433,163 & 379,8 & 384,1 & 404,1 & 426,0 \\
\hline CATALUÑA & $2.588,6$ & $2.673,0$ & $2.727,7$ & $2.589,0$ & $2.455,3$ & $2.460,2$ & $2.375,7$ & $2.276,1$ & $2.098,2$ & $2.166,0$ & $2.259,6$ & $2.364,5$ \\
\hline $\begin{array}{l}\text { CEUTA Y } \\
\text { MELILLA } \\
\end{array}$ & 27,9 & 30,3 & 31,2 & 31,7 & 31,9 & 32,8 & 32,7 & 31,2 & 23,4 & 24,3 & 25,1 & 25,6 \\
\hline $\begin{array}{l}\text { COMUNIDAD DE } \\
\text { MADRID }\end{array}$ & $2.416,7$ & $2.527,8$ & $2.589,2$ & $2.492,1$ & $2.386,9$ & $2.372,7$ & $2.346,5$ & $2.240,4$ & $2.079,0$ & $2.139,6$ & $2.235,0$ & $2.317,1$ \\
\hline $\begin{array}{l}\text { COMUNIDAD } \\
\text { VALENCIANA }\end{array}$ & $1.451,1$ & $1.508,6$ & $1.531,1$ & $1.380,3$ & $1.280,6$ & $1.320,4$ & $1.271,2$ & $1.214,7$ & $1.126,4$ & $1.167,9$ & $1.221,4$ & $1.281,8$ \\
\hline EXTREMADURA & 230,4 & 244,4 & 256,9 & 240,3 & 240,7 & 251,8 & 241,2 & 231,558 & 192,5 & 193,0 & 201,8 & 209,0 \\
\hline GALICIA & 713,9 & 753,5 & 783,2 & 755,3 & 729,1 & 726,2 & 699,0 & 663,33 & 596,5 & 604,4 & 623,7 & 642,6 \\
\hline MURCIA & 387,7 & 410,2 & 418,7 & 376,9 & 351,2 & 393,7 & 378,3 & 361,813 & 343,6 & 359,0 & 378,4 & 396,6 \\
\hline NAVARRA & 203,9 & 213,1 & 222,2 & 215,0 & 207,3 & 208,8 & 204,4 & 194,262 & 180,4 & 184,8 & 190,8 & 195,9 \\
\hline PAÍS VASCO & 715,6 & 738,1 & 759,4 & 745,4 & 722,8 & 723,7 & 713,7 & 680,923 & 622,9 & 631,7 & 650,3 & 667,2 \\
\hline RIOJA (LA) & 92,1 & 95,8 & 98,4 & 93,3 & 89,2 & 91,4 & 88,6 & 84,008 & 76,6 & 79,4 & 82,0 & 85,0 \\
\hline
\end{tabular}

Fuente: Base de Datos de la Economía Social del Ministerio de Empleo y Seguridad Social (fecha de consulta: 06/03/2018) ${ }^{14}$.

${ }^{14}$ Fuente: http://www.empleo.gob.es/estadisticas/COO/welcome.htm. 
Tabla. 3. Número de personas trabajadoras en Cooperativas Inscritas.

\begin{tabular}{|c|c|c|c|c|c|c|c|c|c|c|c|c|}
\hline $\begin{array}{l}\text { COMUNIDADES } \\
\text { AUTÓNOMAS }\end{array}$ & 2005 & 2006 & 2007 & 2008 & 2009 & 2010 & 2011 & 2012 & 2013 & 2014 & 2015 & 2016 \\
\hline ESPAÑA & 237.927 & 243.476 & 240.817 & 235.551 & 224.183 & 226.165 & 218.153 & 214.313 & 213.582 & 214.233 & 220.359 & 230.637 \\
\hline ANDALUCÍA & 54.360 & 54.895 & $\mathbf{5 3 . 5 3 2}$ & 52.928 & 51.734 & 52.549 & 51.960 & 55.445 & 54.150 & 53.126 & 56.489 & 57.434 \\
\hline ARAGÓN & 6.504 & 6.217 & 6.392 & 6.030 & 5.179 & 4.988 & 4.926 & 4.687 & 4.873 & 4.780 & 4.866 & 5.038 \\
\hline ASTURIAS & 3.221 & 3.113 & 3.067 & 2.908 & 3.210 & 3.008 & 2.858 & 2.084 & 2.008 & 2.037 & 2.063 & 2.050 \\
\hline BALEARES & 2.175 & 2.219 & 2.421 & 2.302 & 2.141 & 1.931 & 1.539 & 1.476 & 1.417 & 1.243 & 1.229 & 1.276 \\
\hline CANARIAS & 6.490 & 6.234 & 6.019 & 5.470 & 5.233 & 5.369 & 5.083 & 4.498 & 3.985 & 4.055 & 4.242 & 4.395 \\
\hline CANTABRIA & 1.185 & 1.196 & 1.222 & 1.171 & 1.087 & 1.094 & 959 & 959 & 946 & 975 & 976 & 957 \\
\hline CASTILLA Y LEÓN & 9.751 & 9.724 & 9.741 & 8.986 & 8.690 & 8.513 & 8.065 & 7.512 & 6.704 & 6.702 & 6.715 & 6.891 \\
\hline $\begin{array}{l}\text { CASTILLA-LA } \\
\text { MANCHA }\end{array}$ & 10.976 & 11.492 & 11.095 & 10.184 & 9.266 & 9.253 & 8.914 & 8.130 & 8.407 & 8.612 & 8.794 & 9.112 \\
\hline CATALUÑA & 30.106 & 29.555 & 30.734 & 27.142 & 26.034 & 25.859 & 24.501 & 23.420 & 24.602 & 25.317 & 25.881 & 27.094 \\
\hline CEUTA Y MELILLA & 422 & 398 & 407 & 331 & 362 & 399 & 385 & 382 & 387 & 379 & 355 & 357 \\
\hline $\begin{array}{c}\text { COMUNIDAD DE } \\
\text { MADRID }\end{array}$ & 12.109 & 12.206 & 13.327 & 13.688 & 13.044 & 12.149 & 11.558 & 11.482 & 12.100 & 12.145 & 12.487 & 12.877 \\
\hline $\begin{array}{l}\text { COMUNIDAD } \\
\text { VALENCIANA }\end{array}$ & 45.550 & 49.609 & 46.132 & 48.782 & 45.465 & 46.433 & 42.661 & 41.394 & 41.067 & 40.999 & 40.497 & 45.096 \\
\hline EXTREMADURA & 6.524 & 6.624 & 6.440 & 5.602 & 5.046 & 5.118 & 4.788 & 4.743 & 4.832 & 4.744 & 4.729 & 4.723 \\
\hline GALICIA & 7.096 & 7.045 & 6.957 & 6.805 & 6.566 & 6.747 & 6.418 & 6.384 & 6.491 & 6.399 & 6.452 & 6.465 \\
\hline MURCIA & 15.159 & 15.288 & 15.083 & 14.094 & 13.787 & 13.468 & 12.971 & 12.219 & 12.189 & 12.389 & 13.779 & 14.462 \\
\hline NAVARRA & 3.987 & 4.260 & 4.272 & 4.873 & 4.878 & 5.003 & 5.148 & 5.072 & 4.989 & 5.334 & 5.296 & 5.608 \\
\hline PAÍS VASCO & 20.840 & 21.906 & 22.746 & 23.302 & 21.575 & 23.310 & 24.478 & 23.521 & 23.547 & 24.148 & 24.849 & 26.187 \\
\hline RIOJA (LA) & 1.472 & 1.495 & 1.230 & 953 & 886 & 974 & 941 & 905 & 888 & 849 & 660 & 615 \\
\hline
\end{tabular}

Fuente: Base de Datos de la Economía Social del Ministerio de Empleo y Seguridad Social (fecha de consulta: 06/03/2018) ${ }^{15}$.

${ }^{15}$ Fuente: http://www.empleo.gob.es/estadisticas/COO/welcome.htm. 
Tabla. 4. Tasa de Variación (crecimiento) de las personas trabajadoras en el Total de Empresas Inscritas y Cooperativas.

\begin{tabular}{|c|c|c|c|c|c|c|c|c|}
\hline \multirow[b]{2}{*}{ COMUNIDADES AUTÓNOMAS } & \multicolumn{4}{|c|}{$\begin{array}{l}\text { Tasa de Variación (crecimiento) de las personas trabajadoras en } \\
\text { el Total de Empresas Inscritas }\end{array}$} & \multicolumn{4}{|c|}{$\begin{array}{c}\text { Tasa de Variación (crecimiento) de las personas trabajadoras en } \\
\text { el Total de Cooperativas Inscritas }\end{array}$} \\
\hline & $2005-2016$ & $2005-2007$ & $2008-2015$ & $2015-2016$ & $2005-2016$ & $2005-2007$ & $2008-2015$ & $2015-2016$ \\
\hline ESPAÑA & $-6,45 \%$ & $7,38 \%$ & $-11,00 \%$ & $4,28 \%$ & $-3,06 \%$ & $1,21 \%$ & $-6,45 \%$ & $4,66 \%$ \\
\hline ANDALUCÍA & $2,46 \%$ & $8,22 \%$ & $\mathbf{0 , 1 1 \%}$ & $4,83 \%$ & $5,65 \%$ & $-1,52 \%$ & $6,73 \%$ & $1,67 \%$ \\
\hline ARAGÓN & $-9,49 \%$ & $10,37 \%$ & $-16,13 \%$ & $3,67 \%$ & $-22,54 \%$ & $-1,72 \%$ & $-19,30 \%$ & $3,53 \%$ \\
\hline ASTURIAS & $-13,10 \%$ & $8,41 \%$ & $-19,10 \%$ & $2,74 \%$ & $-36,36 \%$ & $-4,78 \%$ & $-29,06 \%$ & $-0,63 \%$ \\
\hline BALEARES & $-4,07 \%$ & $8,04 \%$ & $-11,12 \%$ & $7,07 \%$ & $-41,33 \%$ & $11,31 \%$ & $-46,61 \%$ & $3,82 \%$ \\
\hline CANARIAS & $-7,47 \%$ & $4,90 \%$ & $-9,24 \%$ & $6,28 \%$ & $-32,28 \%$ & $-7,26 \%$ & $-22,45 \%$ & $3,61 \%$ \\
\hline CANTABRIA & $-10,03 \%$ & $9,75 \%$ & $-16,65 \%$ & $3,85 \%$ & $-19,24 \%$ & $3,12 \%$ & $-16,65 \%$ & $-1,95 \%$ \\
\hline CASTILLA Y LEÓN & $-10,26 \%$ & $8,77 \%$ & $-16,48 \%$ & $2,99 \%$ & $-29,33 \%$ & $-0,10 \%$ & $-25,27 \%$ & $2,62 \%$ \\
\hline CASTILLA-LA MANCHA & $-14,10 \%$ & $13,38 \%$ & $-22,20 \%$ & $5,41 \%$ & $-16,98 \%$ & $1,08 \%$ & $-13,65 \%$ & $3,62 \%$ \\
\hline CATALUÑA & $-8,66 \%$ & $5,37 \%$ & $-12,72 \%$ & $4,64 \%$ & $-10,00 \%$ & $2,09 \%$ & $-4,65 \%$ & $4,69 \%$ \\
\hline CEUTA Y MELILLA & $-8,28 \%$ & $11,83 \%$ & $-20,97 \%$ & $2,14 \%$ & $-15,40 \%$ & $-3,55 \%$ & $7,25 \%$ & $0,56 \%$ \\
\hline COMUNIDAD DE MADRID & $-4,12 \%$ & $7,14 \%$ & $-10,31 \%$ & $3,67 \%$ & $6,34 \%$ & $10,06 \%$ & $-8,77 \%$ & $3,12 \%$ \\
\hline COMUNIDAD VALENCIANA & $-11,67 \%$ & $5,51 \%$ & $-11,51 \%$ & $4,94 \%$ & $-1,00 \%$ & $1,28 \%$ & $-16,98 \%$ & $11,36 \%$ \\
\hline EXTREMADURA & $-9,30 \%$ & $11,51 \%$ & $-16,02 \%$ & $3,55 \%$ & $-27,61 \%$ & $-1,29 \%$ & $-15,58 \%$ & $-0,13 \%$ \\
\hline GALICIA & $-9,98 \%$ & $9,70 \%$ & $-17,42 \%$ & $3,03 \%$ & $-8,89 \%$ & $-1,96 \%$ & $-5,19 \%$ & $0,20 \%$ \\
\hline MURCIA & $2,29 \%$ & $7,99 \%$ & $0,39 \%$ & $4,81 \%$ & $-4,60 \%$ & $-0,50 \%$ & $-2,23 \%$ & $4,96 \%$ \\
\hline NAVARRA & $-3,94 \%$ & $8,97 \%$ & $-11,28 \%$ & $2,68 \%$ & $40,66 \%$ & $7,15 \%$ & $8,68 \%$ & $5,89 \%$ \\
\hline PAÍS VASCO & $-6,76 \%$ & $6,12 \%$ & $-12,76 \%$ & $2,60 \%$ & $25,66 \%$ & $9,15 \%$ & $6,64 \%$ & $5,38 \%$ \\
\hline RIOJA (LA) & $-7,68 \%$ & $6,90 \%$ & $-12,13 \%$ & $3,66 \%$ & $-58,22 \%$ & $-16,44 \%$ & $-30,75 \%$ & $-6,82 \%$ \\
\hline
\end{tabular}

Fuente: Base de Datos de la Economía Social del Ministerio de Empleo y Seguridad Social (fecha de consulta: 06/03/2018) ${ }^{16}$. 


\subsection{Evolución del Número de Empresas y del Número de Cooperativas inscritas}

Este apartado expone la evolución del número de cooperativas en España y sus comunidades autónomas entre 2005 y 2016, comparando las tasas de variación entre ellas, así como, contrastando el crecimiento o decrecimiento progresión de las cooperativas españolas y sus regiones con el resultado del total de empresas (independiente de su forma jurídica).

En la Tabla 6 y 7, se evidencia que en el periodo 2005-2016 se ha reducido significativamente el número de cooperativas inscritas en la Seguridad Social a nivel nacional (26,56\%). En los mismos períodos se han realizado las siguientes observaciones en las regiones:

En el periodo Precrisis (2005-2007), se halla que el volumen de cooperativas aumentó solo en cuatro comunidades autónomas: Castilla La Mancha (0,18\%), Castilla y León (0,72\%), País Vasco (0,63\%) más Ceuta y Melilla $(3,13 \%)$. Las reducciones más acusadas se encuentran en Cataluña $(-11,10 \%)$, La Rioja (-12,20\%), Canarias $(-9,64 \%)$ y Cantabria $(-9,72 \%)$.

Durante el periodo de Crisis (2008-2015), se registra que el número de empresas cooperativas cayó tanto a nivel nacional $(-18,80 \%)$ como en las regiones, menos en Navarra $(21,86 \%)$ y el País Vasco $(25,60 \%)$. Los decrementos más llamativos son los de Ceuta y Melilla $(-42,86 \%)$, La Rioja $(-34,68 \%)$ y Cantabria $(-30,49 \%)$.

En vía de recuperación (2015-2016) aunque la tasa de variación fue positiva en España $(0,69 \%)$ y para muchas de sus regiones, continuó siendo negativas en algunas otras como Ceuta y Melilla (-20\%), La Rioja $(-8,99 \%)$ y Baleares $(-5,17 \%)$.

Los resultados manifiestan que tanto antes como durante la crisis, el número de cooperativas españolas y de muchas de sus comunidades autónomas se redujo. Por otro lado, según las evidencias anteriores, la reducción del volumen de cooperativas no ha implicado en todos los casos una eliminación equivalente de puesto de trabajos, sino que los mismos se han incrementado, como son los casos de Andalucía, Navarra y País Vasco. Por último, las Tablas 5, 6 y 7 favorecen efectuar una comparación entre la evolución del número de cooperativas españolas en las comunidades autónomas respecto al número total de empresas. Se observa que las regiones manifiestan tres tipos de comportamiento que se repiten en los periodos analizados, los cuales de detallan a continuación.

Entre 2005 y 2016, se reconocen doce regiones donde se ha producido una menor destrucción de empresas en el total de empresas: Aragón, Asturias, Baleares, Canarias, Cantabria, Castilla y León, Galicia, Comunidad de Madrid, Murcia, La Rioja, Ceuta y Melilla. También, las cinco de regiones donde se ha producido una mayor creación de empresas en total de empresas: Andalucía, Castilla la Mancha, Cataluña, Comunidad Valenciana y Extremadura, junto al total nacional. Se produce una mayor creación de empresas en cooperativas en dos regiones: Navarra y País Vasco.

De forma disociada, se observan variaciones en los cuatro periodos:

En el periodo Precrisis (2005-2008):

- En todos los casos se han creado más empresas en su conjunto que si se diferencian por cooperativas.

Durante la Crisis (2008-2015):

- Quince regiones registran una menor destrucción de compañías en el total de empresas: Aragón, Asturias, Baleares, Canarias, Cantabria, Castilla la Mancha, Castilla León, Cataluña, Comunidad Valenciana, Galicia, Comunidad de Madrid, Murcia, La Rioja, Ceuta y Melilla.

- Dos regiones originan una mayor creación de compañías en total de empresas: Andalucía, y Extremadura, junto al total nacional.

- En dos regiones donde se ha producido una mayor creación de empresas en cooperativas: Navarra y País Vasco.

En el periodo de Recuperación (2015-2016):

- Las regiones donde se ha producido una mayor creación de compañías en el total de empresas son: Andalucía, Aragón, Asturias, Baleares Canarias, Castilla la Mancha, Castilla León, Cataluña, Comunidad Valenciana, Extremadura, Comunidad de Madrid, Murcia, La Rioja, Ceuta y Melilla. Contiguo al total nacional.

- Tres regiones reconocen una mayor creación de empresas en cooperativas: Cantabria, Navarra y País Vasco. 
Tabla. 5. Número de Empresas Inscritas.

\begin{tabular}{|c|c|c|c|c|c|c|c|c|c|c|c|c|}
\hline $\begin{array}{l}\text { COMUNIDADES } \\
\text { AUTÓNOMAS }\end{array}$ & 2005 & 2006 & 2007 & 2008 & 2009 & 2010 & 2011 & 2012 & 2013 & 2014 & 2015 & 2016 \\
\hline ESPAÑA & 1.347 .758 & 1.386 .157 & 1.405 .938 & 1.332 .090 & 1.264 .689 & 1.323 .810 & 1.300 .992 & 1.257 .128 & 1.293 .523 & 1.303 .823 & 1.336 .540 & 1.364 .107 \\
\hline ANDALUCÍA & 214.771 & 223.654 & 228.483 & 212.650 & 200.812 & 243.261 & 245.614 & 233.779 & 241.212 & 238.565 & 249.727 & 255.615 \\
\hline ARAGÓN & 43.474 & 44.825 & 46.002 & 44.308 & 42.579 & 43.362 & 42.439 & 41.376 & 40.078 & 40.341 & 40.709 & 41.150 \\
\hline ASTURIAS & 30.713 & 31.633 & 32.278 & 31.474 & 30.633 & 30.540 & 29.720 & 28.326 & 27.377 & 27.409 & 27.695 & 27.916 \\
\hline BALEARES & 36.364 & 37.409 & 38.162 & 36.247 & 34.461 & 34.392 & 33.497 & 32.904 & 32.472 & 33.226 & 34.472 & 35.670 \\
\hline CANARIAS & 63.029 & 64.300 & 64.769 & 60.682 & 57.121 & 58.105 & 58.122 & 57.172 & 56.704 & 57.478 & 58.341 & 60.434 \\
\hline CANTABRIA & 18.050 & 18.801 & 19.116 & 18.500 & 17.894 & 17.933 & 17.394 & 16.660 & 16.064 & 16.210 & 16.494 & 16.654 \\
\hline CASTILLA Y LEÓN & 73.190 & 75.947 & 77.885 & 75.378 & 73.095 & 75.502 & 73.664 & 70.774 & 67.081 & 67.511 & 67.889 & 68.612 \\
\hline CASTILLA-LA MANCHA & 57.399 & 60.409 & 63.009 & 58.856 & 55.246 & 61.477 & 59.360 & 56.325 & 56.813 & 56.230 & 57.988 & 59.416 \\
\hline CATALUÑA & 253.803 & 258.232 & 260.028 & 246.493 & 233.079 & 232.097 & 226.890 & 219.551 & 215.037 & 218.258 & 222.197 & 227.795 \\
\hline CEUTA Y MELILLA & 3.219 & 3.328 & 3.396 & 3.380 & 3.375 & 3.493 & 3.442 & 3.500 & 3.246 & 3.309 & 3.345 & 3.391 \\
\hline $\begin{array}{c}\text { COMUNIDAD DE } \\
\text { MADRID }\end{array}$ & 192.767 & 196.570 & 198.479 & 191.283 & 183.732 & 181.377 & 177.281 & 173.126 & 170.906 & 174.039 & 178.353 & 181.906 \\
\hline $\begin{array}{l}\text { COMUNIDAD } \\
\text { VALENCIANA }\end{array}$ & 159.617 & 164.425 & 165.422 & 153.127 & 141.366 & 141.585 & 137.846 & 133.615 & 132.885 & 136.176 & 140.344 & 144.090 \\
\hline EXTREMADURA & 26.182 & 27.678 & 28.738 & 27.725 & 26.848 & 31.329 & 30.944 & 30.935 & 30.195 & 30.066 & 30.990 & 31.634 \\
\hline GALICIA & 85.678 & 87.868 & 89.601 & 87.472 & 84.715 & 87.495 & 85.233 & 82.041 & 80.118 & 80.300 & 81.054 & 81.858 \\
\hline MURCIA & 44.117 & 46.391 & 46.952 & 42.776 & 39.552 & 41.224 & 40.086 & 38.986 & 38.818 & 39.423 & 40.629 & 41.239 \\
\hline NAVARRA & 18.471 & 18.894 & 19.144 & 18.697 & 17.954 & 18.564 & 18.059 & 17.607 & 16.877 & 16.968 & 17.213 & 17.305 \\
\hline PAÍS VASCO & 63.049 & 64.075 & 64.500 & 63.081 & 61.576 & 61.904 & 60.873 & 59.024 & 57.442 & 58.062 & 58.700 & 58.951 \\
\hline RIOJA (LA) & 10.903 & 11.197 & 11.468 & 11.089 & 10.753 & 11.148 & 10.875 & 10.505 & 10.198 & 10.252 & 10.400 & 10.471 \\
\hline
\end{tabular}

Fuente: Base de Datos de la Economía Social del Ministerio de Empleo y Seguridad Social (fecha de consulta: 06/03/2018) ${ }^{17}$.

${ }^{17}$ Fuente: http://www.empleo.gob.es/estadisticas/COO/welcome.htm. 
Tabla. 6. Número de Cooperativas Inscritas.

\begin{tabular}{|c|c|c|c|c|c|c|c|c|c|c|c|c|}
\hline $\begin{array}{l}\text { COMUNIDADES } \\
\text { AUTÓNOMAS }\end{array}$ & 2005 & 2006 & 2007 & 2008 & 2009 & 2010 & 2011 & 2012 & 2013 & 2014 & 2015 & 2016 \\
\hline ESPAÑA & 16.391 & 15.954 & 15.524 & 14.825 & 13.701 & 13.310 & 12.720 & 12.095 & 11.862 & 11.838 & 11.956 & 12.038 \\
\hline ANDALUCÍA & 4.303 & 4.191 & 4.075 & 3.814 & 3.442 & 3.245 & 3.068 & 2.864 & 2.753 & 2.739 & 2.743 & 2.710 \\
\hline ARAGÓN & 591 & 585 & 561 & 536 & 489 & 482 & 463 & 443 & 442 & 430 & 425 & 423 \\
\hline ASTURIAS & 223 & 216 & 213 & 201 & 201 & 193 & 179 & 171 & 164 & 162 & 169 & 168 \\
\hline BALEARES & 124 & 123 & 120 & 128 & 125 & 123 & 112 & 116 & 114 & 112 & 116 & 110 \\
\hline CANARIAS & 332 & 312 & 300 & 283 & 257 & 243 & 239 & 226 & 208 & 203 & 199 & 202 \\
\hline CANTABRIA & 72 & 70 & 65 & 82 & 53 & 57 & 51 & 53 & 52 & 54 & 56 & 57 \\
\hline CASTILLA Y LEÓN & 1.117 & 1.137 & 1.125 & 1.127 & 1.080 & 1.062 & 1.036 & 985 & 964 & 953 & 945 & 949 \\
\hline CASTILLA-LA MANCHA & 1.100 & 1.094 & 1.102 & 1.060 & 995 & 979 & 929 & 863 & 868 & 862 & 860 & 853 \\
\hline CATALUÑA & 2.586 & 2.428 & 2.299 & 2.104 & 1.919 & 1.862 & 1.744 & 1.614 & 1.546 & 1.534 & 1.503 & 1.538 \\
\hline CEUTA Y MELILLA & 32 & 34 & 33 & 28 & 31 & 30 & 26 & 26 & 24 & 21 & 20 & 16 \\
\hline COMUNIDAD DE MADRID & 818 & 750 & 744 & 719 & 671 & 649 & 625 & 597 & 603 & 591 & 591 & 599 \\
\hline COMUNIDAD VALENCIANA & 1.741 & 1.714 & 1.657 & 1.549 & 1.416 & 1.361 & 1.250 & 1.200 & 1.194 & 1.198 & 1.230 & 1.260 \\
\hline EXTREMADURA & 609 & 602 & 601 & 586 & 560 & 539 & 527 & 526 & 511 & 523 & 516 & 512 \\
\hline GALICIA & 675 & 674 & 632 & 653 & 596 & 595 & 574 & 572 & 566 & 569 & 579 & 566 \\
\hline MURCIA & 972 & 941 & 918 & 855 & 816 & 802 & 787 & 723 & 711 & 694 & 757 & 775 \\
\hline NAVARRA & 184 & 182 & 177 & 183 & 174 & 181 & 182 & 184 & 191 & 199 & 205 & 223 \\
\hline PAÍS VASCO & 789 & 782 & 794 & 793 & 774 & 809 & 833 & 845 & 859 & 905 & 953 & 996 \\
\hline RIOJA (LA) & 123 & 119 & 108 & 124 & 102 & 98 & 95 & 87 & 92 & 89 & 89 & 81 \\
\hline
\end{tabular}

Fuente: Base de Datos de la Economía Social del Ministerio de Empleo y Seguridad Social (fecha de consulta: 06/03/2018) ${ }^{18}$.

${ }^{18}$ Fuente: http://www.empleo.gob.es/estadisticas/COO/welcome.htm. 
Tabla. 7. Tasa de Variación (crecimiento) de las personas trabajadoras en el Total de Empresas Inscritas y Cooperativas.

\begin{tabular}{|c|c|c|c|c|c|c|c|c|}
\hline \multirow[b]{2}{*}{ COMUNIDADES AUTÓNOMAS } & \multicolumn{4}{|c|}{ Tasa de Variación (crecimiento) del Total de Empresas Inscritas } & \multicolumn{4}{|c|}{ Tasa de Variación (crecimiento) del Total de Cooperativas Inscritas } \\
\hline & $2005-2016$ & $2005-2007$ & $2008-2015$ & $2015-2016$ & $2005-2016$ & $2005-2007$ & $2008-2015$ & $2015-2016$ \\
\hline ESPAÑA & $1,21 \%$ & $4,32 \%$ & $0,33 \%$ & $2,06 \%$ & $-26,56 \%$ & $-5,29 \%$ & $-18,80 \%$ & $0,69 \%$ \\
\hline ANDALUCÍA & $19,02 \%$ & $6,38 \%$ & $17,44 \%$ & $2,36 \%$ & $-37,02 \%$ & $-5,30 \%$ & $-28,95 \%$ & $-1,20 \%$ \\
\hline ARAGÓN & $-5,35 \%$ & $5,81 \%$ & $-8,12 \%$ & $1,08 \%$ & $-28,43 \%$ & $-5,08 \%$ & $-21,08 \%$ & $-0,47 \%$ \\
\hline ASTURIAS & $-9,11 \%$ & $5,10 \%$ & $-12,01 \%$ & $0,80 \%$ & $-24,66 \%$ & $-4,48 \%$ & $-16,42 \%$ & $-0,59 \%$ \\
\hline BALEARES & $-1,91 \%$ & $4,94 \%$ & $-4,90 \%$ & $3,48 \%$ & $-11,29 \%$ & $-3,23 \%$ & $-14,06 \%$ & $-5,17 \%$ \\
\hline CANARIAS & $-4,12 \%$ & $2,76 \%$ & $-3,86 \%$ & $3,59 \%$ & $-39,16 \%$ & $-9,64 \%$ & $-28,62 \%$ & $1,51 \%$ \\
\hline CANTABRIA & $-7,73 \%$ & $5,91 \%$ & $-10,84 \%$ & $0,97 \%$ & $-20,83 \%$ & $-9,72 \%$ & $-30,49 \%$ & $1,79 \%$ \\
\hline CASTILLA Y LEÓN & $-6,25 \%$ & $6,41 \%$ & $-9,94 \%$ & $1,06 \%$ & $-15,04 \%$ & $0,72 \%$ & $-15,79 \%$ & $0,42 \%$ \\
\hline CASTILLA-LA MANCHA & $3,51 \%$ & $9,77 \%$ & $-1,47 \%$ & $2,46 \%$ & $-22,45 \%$ & $0,18 \%$ & $-19,53 \%$ & $-0,81 \%$ \\
\hline CATALUÑA & $-10,25 \%$ & $2,45 \%$ & $-9,86 \%$ & $2,52 \%$ & $-40,53 \%$ & $-11,10 \%$ & $-26,90 \%$ & $2,33 \%$ \\
\hline CEUTA Y MELILLA & $5,34 \%$ & $5,50 \%$ & $-1,04 \%$ & $1,38 \%$ & $-50,00 \%$ & $3,13 \%$ & $-42,86 \%$ & $-20,00 \%$ \\
\hline COMUNIDAD DE MADRID & $-5,63 \%$ & $2,96 \%$ & $-6,76 \%$ & $1,99 \%$ & $-26,77 \%$ & $-9,05 \%$ & $-16,69 \%$ & $1,35 \%$ \\
\hline COMUNIDAD VALENCIANA & $-9,73 \%$ & $3,64 \%$ & $-8,35 \%$ & $2,67 \%$ & $-27,63 \%$ & $-4,82 \%$ & $-18,66 \%$ & $2,44 \%$ \\
\hline EXTREMADURA & $20,82 \%$ & $9,76 \%$ & $11,78 \%$ & $2,08 \%$ & $-15,93 \%$ & $-1,31 \%$ & $-12,63 \%$ & $-0,78 \%$ \\
\hline GALICIA & $-4,46 \%$ & $4,58 \%$ & $-7,34 \%$ & $0,99 \%$ & $-16,15 \%$ & $-6,37 \%$ & $-13,32 \%$ & $-2,25 \%$ \\
\hline MURCIA & $-6,52 \%$ & $6,43 \%$ & $-5,02 \%$ & $1,50 \%$ & $-20,27 \%$ & $-5,56 \%$ & $-9,36 \%$ & $2,38 \%$ \\
\hline NAVARRA & $-6,31 \%$ & $3,64 \%$ & $-7,94 \%$ & $0,53 \%$ & $21,20 \%$ & $-3,80 \%$ & $21,86 \%$ & $8,78 \%$ \\
\hline PAÍS VASCO & $-6,50 \%$ & $2,30 \%$ & $-6,95 \%$ & $0,43 \%$ & $26,24 \%$ & $0,63 \%$ & $25,60 \%$ & $4,51 \%$ \\
\hline RIOJA (LA) & $-3,96 \%$ & $5,18 \%$ & $-6,21 \%$ & $0,68 \%$ & $-34,15 \%$ & $-12,20 \%$ & $-34,68 \%$ & $-8,99 \%$ \\
\hline
\end{tabular}

Fuente: Base de Datos de la Economía Social del Ministerio de Empleo y Seguridad Social (fecha de consulta: 06/03/2018) ${ }^{19}$. 


\subsection{Análisis Shift-Share}

Para comprender el motivo de la evolución del número de personas trabajando en cooperativas inscritas en la Seguridad Social se realiza un análisis Shift-Share, y así determinar los efectos provocados por la variación de empleos en las cooperativas de España y sus comunidades autónomas. Según los resultados del análisis Shift-Share, que se presentan en la Tabla 5, se constatan cuatro tendencias:

Entre 2005-2016, la tasa de variación fue positiva. Se observa un crecimiento del número de personas trabajadoras en las cooperativas andaluzas, madrileñas, navarras y vascas a partir del efecto competitivo y dinámico. Es decir, aumentó en mayor cuantía el número de personas empleadas en cooperativas en esas regiones que en España, mientras que a nivel nacional la reducción de puestos de trabajo fue menor en las cooperativas. Para el resto de regiones el efecto total abarcó valores negativos, lo cual no fue debido al efecto dinámico ya que resultó positivo para todos los casos, sino a la falta de competitividad de las cooperativas a nivel regional y la carencia nacional para generar empleo.

En el periodo Precrisis (2005-2007), la tasa de variación fue positiva para ocho regiones (Baleares, Cantabria, Castilla La Mancha, Comunidad de Madrid, Cataluña, Comunidad Valenciana, Navarra y País Vasco). Todas estas regiones, excepto Castilla La Mancha, presentaron la misma justificación: efecto nacional y competitivo positivo. Así pues, el crecimiento de contratos en cooperativas se debió tanto al propio crecimiento nacional como al aumento de la contratación de las cooperativas en dichas regiones. La Comunidad Valenciana debe la totalidad de su incremento a la inercia nacional. En este caso los resultados negativos se justifican a través de los efectos competitivos y dinámicos, por lo que revela la debilidad de esas cooperativas para incrementar su plantilla.

Durante la Crisis (2008-2015), las personas trabajadoras de cooperativas andaluzas, navarras y vascas, junto a las regiones de Ceuta y Melilla, aumentaron debido al efecto dinámico y competitivo. Al igual que entre 2005-2016, se incrementó en mayor cuantía el número de personas empleadas en las cooperativas de esas regiones que en España. A su vez, a nivel nacional la reducción de puestos de trabajo fue menor en las cooperativas. En similitud a lo acontecido entre 2005-2016, los motivos de los resultados negativos son principalmente a los efectos competitivos y dinámicos.

La evolución del número de personas trabajando en cooperativas entre 2015 y 2016 resultó positiva en muchas regiones, pero los motivos que derivaron esta situación son difieren. Se observan dos grupos: 1) aquellas regiones que debieron su crecimiento al efecto nacional y dinámico, 2) aquellas regiones que fundamentan su incremento en el efecto nacional, dinámico y competitivo. Dentro del grupo $1 \mathrm{se}$ encuentran: Andalucía, Aragón, Baleares, Canarias, Castilla La Mancha, Galicia, Comunidad de Madrid, Castilla y León, Ceuta y Melilla. En estas regiones, la propia inercia del aumento de personas trabajadoras en cooperativas en España ha derivado en un incremento a nivel autonómico y, además, a nivel nacional el aumento de puestos de trabajo fue superior en las cooperativas. El grupo 2 está compuesto por Cataluña, Comunidad Valenciana, Murcia, Navarra y País Vasco. Este grupo atestigua un incremento nacional y regional de las personas empleadas en las cooperativas. Los resultados negativos se justifican por la falta de capacidad de generar empleo en las cooperativas de las comunidades autónomas en cuestión.

Hay que destacar a las regiones que manifestaron un efecto total y tasa de variación positiva. Andalucía reconoce un efecto dinámico, y común, durante tres periodos estudiados, es decir, el empleo cooperativo aumenta debido al incremento a nivel nacional del trabajo en las cooperativas frente al empleo del total de empresas. En cambio, para País Vasco y Navarra el elemento común fue el efecto competitivo, lo que revela el mayor potencial de las sociedades cooperativas para mantener y aumentar el empleo.

A tenor de los resultados expuestos, las cooperativas se revelan como las empresas con mayor capacidad de generar empleo que el resto de formas jurídicas, especialmente en algunas regiones como Andalucía, Navarra y País Vasco.

En la economía española el impacto de la crisis en las tasas de desempleo es mayor que la media de los países de la Unión Europea. En el año 2008, las tasas de paro en España superaron el 60\% con respecto a la Unión Europea y en plena crisis (Año $2010^{20}$ ) la tasa de paro duplicó la comunitaria y la destrucción de empleo fue casi seis veces superior (Calderón y Calderón, 2012b). Este contexto trasladado a las cooperativas, conduce a destacar, por otras autorías, que el comportamiento procíclico de las cooperativas es

20 Durante 2010, las cooperativas en España incrementan su plantilla en un $0,2 \%$ con respecto al año anterior, reflejando en plena crisis las cooperativas son capaces de crear empleo (Calderón y Calderón, 2012b). 
menos sensible a la fase del ciclo que el empleo total de la economía española. Esto significa que, mientras en fases expansivas las cooperativas se muestran menos dinámicas en la generación de empleo que el conjunto de la economía española; en periodos recesivos, la destrucción de empleo en ellas es mucho menor (Díaz-Foncea y Marcuello-Servós, 2010). Esta afirmación se verifica en la región de Andalucía.

Sobre la premisa de que el empleo en las cooperativas es menos sensible en tiempos de crisis concurren dos planteamientos. Por un lado, disponer de personal con mejor capacidad para adaptarse a nuevas jornadas laborales y ajustes de los salarios para evitar despidos; y por otro, la trasformación de empresa tradicional en empresa de ES. Ante la existencia de un aumento considerable de personas desempleadas, la creación de una entidad de ES se registra como salida profesional (Grávalos y Pomares, 2001; Chaves y Monzón, 2007; Calderón y Calderón, 2012b). Especialmente en tiempos de crisis, las cooperativas y empresas de ES tienen un valor esencial en la comunidad (empleos de calidad, mejora de la cohesión social, generación de capital social, etc.). Así, durante los últimos años se han creado numerosas cooperativas industriales y de servicio, salvando y revitalizando así actividades económicas y puestos de trabajo a escala local. Se evidencia que las cooperativas pueden ser incluso más resistentes que muchas empresas convencionales en tiempos de crisis, debido a la propiedad colectiva y a la acumulación de capital independiente (Toia, 2013:4-5). 
Pérez-Suárez, M.; Sánchez-Torné, I. Revesco (136) 2020: 1-19

Tabla. 8. Análisis Shift-Share del Número de personas trabajadoras en sociedades Cooperativas.

\begin{tabular}{|c|c|c|c|c|c|c|c|c|c|c|c|c|c|c|c|c|}
\hline & \multicolumn{4}{|c|}{$2005-2016$} & \multicolumn{4}{|c|}{$2005-2007$} & \multicolumn{4}{|c|}{$2008-2015$} & \multicolumn{4}{|c|}{$2015-2016$} \\
\hline & Efecto total & Efecto nacional & Efecto competitivo & Efecto dinámico & Efecto total & Efecto nacional & $\begin{array}{c}\text { Efecto } \\
\text { competitivo } \\
\end{array}$ & $\begin{array}{c}\text { Efecto } \\
\text { dinámico }\end{array}$ & $\begin{array}{c}\text { Efecto } \\
\text { total }\end{array}$ & $\begin{array}{c}\text { Efecto } \\
\text { nacional }\end{array}$ & $\begin{array}{c}\text { Efecto } \\
\text { competitivo } \\
\end{array}$ & $\begin{array}{c}\text { Efecto } \\
\text { dinámico }\end{array}$ & Efecto total & $\begin{array}{c}\text { Efecto } \\
\text { nacional }\end{array}$ & $\begin{array}{c}\text { Efecto } \\
\text { competitivo }\end{array}$ & $\begin{array}{c}\text { Efecto } \\
\text { dinámico }\end{array}$ \\
\hline ANDALUCÍA & 3247,8 & $-3702,8$ & 5007,6 & 1943,0 & $-815,4$ & 3948,6 & $-1465,6$ & $-3298,4$ & 3800,6 & $-6215,2$ & 7443,9 & 2571,9 & 960,8 & 2455,5 & $-1718,0$ & 223,3 \\
\hline ASTURIAS & $-745,3$ & $-132,2$ & $-682,5$ & 69,4 & $-146,6$ & 226,2 & $-183,9$ & $-189,0$ & $-599,5$ & $-227,0$ & $-466,4$ & 93,9 & $-12,9$ & 87,6 & $-108,5$ & 8,0 \\
\hline BALEARES & $-527,4$ & $-82,3$ & $-488,3$ & 43,2 & 273,8 & 178,6 & 244,4 & $-149,2$ & $-572,9$ & $-135,2$ & $-493,6$ & 56,0 & 48,8 & 54,6 & $-10,7$ & 5,0 \\
\hline CANARIAS & $-1418,7$ & $-283,3$ & $-1284,1$ & 148,7 & $-436,8$ & 444,0 & $-509,9$ & $-370,9$ & $-952,3$ & $-466,7$ & $-678,7$ & 193,1 & 158,5 & 187,9 & $-46,5$ & 17,1 \\
\hline CANTABRIA & $-184,1$ & $-61,7$ & $-154,8$ & 32,4 & 38,2 & 90,1 & 23,3 & $-75,3$ & $-162,5$ & $-107,4$ & $-99,6$ & 44,4 & $-18,6$ & 40,9 & $-63,3$ & 3,7 \\
\hline CASTILLA Y LEÓN & $-2021,2$ & $-444,3$ & $-1810,0$ & 233,1 & $-10,0$ & 718,5 & $-128,3$ & $-600,2$ & $-1697,1$ & $-738,8$ & $-1264,0$ & 305,7 & 180,6 & 294,6 & $-140,8$ & 26,8 \\
\hline $\begin{array}{l}\text { CASTILLA-LA } \\
\text { MANCHA }\end{array}$ & $-1547,4$ & $-587,5$ & $-1268,3$ & 308,3 & 120,3 & 818,4 & $-14,5$ & $-683,6$ & $-1200,3$ & $-967,6$ & $-633,1$ & 400,4 & 329,5 & 389,6 & $-95,5$ & 35,4 \\
\hline CATALUÑA & $-2710,7$ & $-1746,8$ & $-1880,5$ & 916,6 & 641,1 & 2267,0 & 267,8 & $-1893,7$ & $-1202,4$ & $-2847,5$ & 466,8 & 1178,3 & 1269,9 & 1158,4 & 6,1 & 105,3 \\
\hline CEUTA Y MELILLA & $-55,0$ & $-23,0$ & $-44,0$ & 12,1 & $-14,5$ & 30,0 & $-19,4$ & $-25,1$ & 25,7 & $-39,1$ & 48,6 & 16,2 & 2,0 & 15,3 & $-14,6$ & 1,4 \\
\hline $\begin{array}{c}\text { COMUNIDAD DE } \\
\text { MADRID } \\
\end{array}$ & 816,7 & $-830,2$ & 1211,3 & 435,6 & 1340,5 & 983,0 & 1178,6 & $-821,1$ & $-1095,6$ & $-1373,9$ & $-290,3$ & 568,5 & 402,2 & 550,5 & $-198,4$ & 50,1 \\
\hline $\begin{array}{l}\text { COMUNIDAD } \\
\text { VALENCIANA } \\
\end{array}$ & $-449,5$ & $-2907,4$ & 932,3 & 1525,6 & 589,4 & 3402,8 & 29,1 & $-2842,4$ & $-6877,9$ & $-4455,7$ & $-4266,0$ & 1843,8 & 5121,3 & 1928,0 & 3017,9 & 175,3 \\
\hline GALICIA & $-574,9$ & $-416,8$ & $-376,8$ & 218,7 & $-136,3$ & 513,2 & $-220,8$ & $-428,7$ & $-334,7$ & $-709,9$ & 81,4 & 293,8 & 13,0 & 276,4 & $-288,5$ & 25,1 \\
\hline MURCIA & $-665,0$ & $-932,4$ & $-221,8$ & 489,3 & $-75,6$ & 1112,6 & $-258,8$ & $-929,3$ & $-308,0$ & $-1516,0$ & 580,7 & 627,3 & 716,9 & 618,3 & 42,3 & 56,2 \\
\hline NAVARRA & 2280,1 & $-361,5$ & 2451,9 & 189,7 & 305,4 & 315,1 & 253,5 & $-263,2$ & 459,7 & $-582,7$ & 801,3 & 241,1 & 330,4 & 239,8 & 68,8 & 21,8 \\
\hline PAÍS VASCO & 6718,9 & $-1688,3$ & 7521,3 & 885,9 & 2080,3 & 1677,8 & 1804,0 & $-1401,5$ & 1649,7 & $-2734,0$ & 3252,4 & 1131,3 & 1410,0 & 1119,6 & 188,6 & 101,8 \\
\hline RIOJA (LA) & $-358,1$ & $-39,6$ & $-339,2$ & 20,8 & $-202,2$ & 90,7 & $-217,2$ & $-75,8$ & $-202,9$ & $-72,6$ & $-160,4$ & 30,0 & $-41,9$ & 26,3 & $-70,6$ & 2,4 \\
\hline
\end{tabular}

Fuente: Elaboración Propia a partir de los datos de la Base de Datos de la Economía Social del Ministerio de Empleo y Seguridad Social (fecha de consulta: 06/03/2018). ${ }^{21}$

\footnotetext{
${ }^{21}$ Fuente: http://www.empleo.gob.es/estadisticas/COO/welcome.htm.
} 


\section{Conclusiones}

Las cooperativas andaluzas, durante un período de recesión, destruyen menos empleo que las empresas no implícitas de la Economía Social. Entre 2005 y 2016, han mantenido el empleo e incluso han generado nuevos puestos de trabajo, tal como indica el incremento de un 6,73\% del volumen de personas empleadas durante la última crisis, este aumento supera a la media nacional. Da lugar a que Andalucía registre un efecto dinámico en la creación de empleo cooperativo, es decir, las cooperativas andaluzas tienen una significativa capacidad de generar empleo.

Las tendencias detalladas muestran que, en un período de recesión, la destrucción de empleos tiende a ser inferior en las cooperativas que en el resto de las empresas mercantiles para Andalucía, Navarra y País Vasco. Asimismo, se trataría de un comportamiento "amortiguador" de la recesión, pues en relación a la generación de empleo es diferente a nivel territorial, es decir, la correlación regional y supraterritorial no es directamente proporcional. Sin duda, el análisis objeto focaliza la interacción significativa entre el empleo de las cooperativas y el ciclo económico, ya que, con él, se alcanza el objetivo de la investigación.

Andalucía, Comunidad de Madrid, Navarra y País Vasco han mantenido el empleo en las sociedades cooperativas entre 2005 y 2016, e incluso generan nuevos puestos de trabajo en mayor grado que las cooperativas españolas en su conjunto. Concretamente, en la época de crisis las cooperativas andaluzas incrementaron el volumen de personas empleadas en un 6,73\%, las sociedades navarras un 8,68\% y las vascas un 6,64\%; mientras que, en España se redujo un 6,45\%. Se puede intuir que las cooperativas de estas comunidades autónomas presentan una gestión congruente de su capital humano que ha posibilitado mantener el empleo en épocas de crisis. De tal modo, se configuran como las regiones de mayor potencial para crear puestos de trabajos en las cooperativas. Además, Navarra y País Vasco incrementaron su número de cooperativas inscritas, no ha sido el caso de Andalucía, una diferencia que evidencia que existen diferentes modelos cooperativistas y desiguales formas de gestión. Por ejemplo, siendo Andalucía un territorio próspero en patrimonio natural, la Economía Verde ofrece posibilidades reales de innovación productiva, crecimiento económico y creación de empleo de calidad (Ramos-Díaz, 2016). Tal como prueba Valiente (2019:67), el cooperativismo andaluz es una oportunidad para mermar la despoblación de municipios rurales mediante la creación de empleo estable.

Se hace patente que no existe un comportamiento homogéneo entre las diferentes comunidades autónomas. Tal como ha sido citado, las cooperativas de Andalucía, Navarra y País Vasco poseen mejor capacidad para mantener y generar empleo, especialmente en fase de crisis, que el total de empresas con independencia de su forma jurídica. Durante el periodo de crisis (2008-2015), las cooperativas de España en su conjunto, Castilla La Mancha, Cataluña, Extremadura, Galicia y Comunidad de Madrid, destruyeron menos empleos que el total de empresas. En fase de recesión, las cooperativas crean nuevos puestos de trabajo en cuatro comunidades autónomas mientras que en el total de empresas solo acontece en Murcia. Sin embargo, para llegar a averiguaciones clarificadoras sobre el decremento del número de cooperativas se requeriría contar con datos que no están disponibles, como, por ejemplo, el número de fusiones y adquisiciones de cooperativas. Es preciso añadir que, en el caso de Andalucía, la Ley de Sociedades Cooperativas Andaluzas (diciembre, 2011) contempla la posibilidad de conformar cooperativas mixtas y grupos de cooperativas, lo que probablemente ha podido potenciar la unión de diversas entidades en una de grado superior. En último lugar, los datos mencionados indican que Navarra y País Vasco realizan una gestión de la política económica más eficiente que se reflejó en el incremento del número de cooperativas y empleo en todos los periodos analizados. El conjunto de pesquisas expuesto supone desde una motivación para impulsar el cooperativismo en Andalucía hasta un mejor conocimiento del empleo generado por las cooperativas de las regiones, a considerar en el diseño de estrategias y políticas activas empleo (Pérez y Valiente, 2019).

Por otra parte, mediante el análisis Shift-Share se halla que el efecto dinámico es un elemento común que propicia el aumento del empleo en las sociedades cooperativas andaluzas, pues el empleo incrementa en mayor proporción en las cooperativas que en el total de empresas. Esto coincide con las conclusiones anteriores y permite destacar que durante los años de crisis se incrementó, en mayor cuantía, el número de personas empleadas en cooperativas de Andalucía que en España y que, a nivel nacional, la reducción de puestos de trabajo fue menor en las cooperativas. En cambio, las cooperativas de Navarra y País Vasco poseen como elemento común en todos los periodos analizados el efecto competitivo, pues denota un punto diferenciador con las cooperativas andaluzas. Así mismo, revela que el aumento de personas trabajadoras en las cooperativas de estas regiones es debido a su propia gestión y no a factores nacionales. No obstante, no todos los resultados son positivos, ya que hubo regiones (entre las que destacan Asturias, Baleares, Castilla y León) donde la reducción de empleo sufrida por las cooperativas durante la crisis fue significativa en el conjunto de empresas. Es preciso matizar estos resultados, ya que las cooperativas andaluzas, navarras y vascas fueron las únicas organizaciones (a excepción de las sociedades murcianas) que durante la recisión mostraron su capacidad de generar empleo. 
Finalmente, se destaca que las cooperativas han demostrado ser un tipo de empresa que ha mantenido y generado empleo, especialmente durante la crisis económica. Las cooperativas andaluzas, junto con las navarras y vascas evidencian mayor potencial. Esto permite destacar el papel de la ES como un agente endógeno y dinamizador del desarrollo territorial sostenible, sin olvidar el apoyo institucional a tal fin (Camacho, Ruiz y Minguela, 2015; Pérez y Valiente, 2019). Así, se valoriza la influencia de las cooperativas en su entorno por su potencialidad para generar riqueza y distribuirla de forma más equitativa. Estas empresas son agentes de desarrollo local por su arraigado y pertenencia a la comunidad (Esteban, Pérez y Gargallo, 2018), junto a la propiedad colectiva, el espíritu emprendedor, y la cooperación empresarial (Calvo-Palomares y González Cardona, 2011). En ese mismo sentido, Sanchis y Campos (2005:282), señalan la consideración de la cooperativa como una fórmula idónea para el desarrollo del potencial endógeno de una zona.

Las premisas probadas permiten plantear la necesidad de profundizar y caracterizar las cooperativas de las regiones para conocer las diferencias entre ellas y aprovechar, eventualmente, los factores determinantes de la acentuación del número de personas empleadas y el número de sociedades. Asimismo, otra línea de investigación venidera sería la posibilidad de realizar un estudio longitudinal amplio y exhaustivo de las últimas décadas ampliando el alcance territorial a la Unión Europea, u otras regiones. Mientras que, una tercera línea sería replicar el estudio en todas las figuras jurídicas de la Economía Social. Este futuro conjeturado pasa por intensificar el conocimiento relacional entre la ES y el desarrollo territorial, lo que, a su vez, requiere incrementar el número de variables explicativas que puedan sostener las tendencias encontradas.

\section{Referencias bibliográficas}

Albuquerque, P., \& Ferreira, J. (2015) Envelhecimento, emprego e remunerações nas regiões portuguesas: uma análise shift-share. EURE (Santiago), No 41 (122), pp. 239-260. http://dx.doi.org/10.4067/S0250-71612015000100011.

Belda, J. I., \& Pérez-Suárez, M. (2018) The international competitiveness of the andalusian economy and its exporting sectors. Cuadernos de Economía, No 41 (116), pp. 207-224. https://doi.org/10.32826/cude.v42i116.67.

Blanco-Canto, M. (2017) Efectos de la crisis económica de 2008 sobre el empleo en las cooperativas andaluzas: un estudio del impacto provincial mediante el análisis shift-share. CIRIEC-España, Revista de Economía Pública, Social y Cooperativa, No 91, pp. 175-201. DOI: 10.7203/CIRIEC-E.91.8196.

Calderón, B., \& Calderón, M. J. (2012a) La calidad del empleo de las entidades de la Economía Social en período de crisis. EKONOMIAZ. Revista Vasca de Economía, № 79 (01), pp. 31-58.

Calderón, B., \& Calderón, M.J. (2012b) Como afrontar la crisis las cooperativas en España: comparativa de trayectorias laborales a partir de la muestra continua de vidas laborales. CIRIEC-España, Revista de Economía Pública, Social y Cooperativa, $\mathrm{N}^{\circ} 76$, pp. 5-26.

Calvo-Palomares, R., \& González-Cardona, J. (2011) La creación de empresas de Economía Social en el modelo de desarrollo local; reflexiones sobre la divergencia actual del caso Valenciano. REVESCO. Revista de Estudios Cooperativos, Primer Cuatrimestre, No 104, pp. 7-37. DOI: 10.5209/rev_REVE.2011.v104.1.

Camacho, J. A., Ruiz, S., \& Minguela, M.Á. (2015) Care giving to dependent people. A source of jobs in times of crisis. The case of Spain. Cuadernos de Relaciones Laborales, $\mathrm{N}^{\circ} 33$ (1), pp. 169-188.

Castro, R. B., Santero, R., Martínez, M. I., \& Guilló, N. (2013) Impacto socioeconómico de las empresas de Economía Social en España. Una valoración cuantitativa de sus efectos sobre la cohesión social. CIRIEC-España, Revista de Economía Pública, Social y Cooperativa, № 79, pp. 35-58.

Chaves, R., \& Demoustier, D. (2013) The emergence of social economy in public policy. An International Perspective. Bruxelles: Peterlang Publishers. Disponible en https://www.peterlang.com/view/product/61593.

Chaves, R., \& Monzón, J.L (2007) La Economía Social en la Unión Europea, CESE/COMM/05/2005, Comité Económico y Social Europeo.

Cieślak, I., Pawlewicz, K., \& Pawlewicz, A. (2019) Sustainable Development in Polish Regions: A Shift-Share Analysis. Polish Journal of Environmental Studies, N$^{\circ} 28$ (2), pp. 1-11. DOI: 10.15244/pjoes/85206.

Clemente-López, J., Díaz-Foncea, M., González-Álvarez, M.A., Marcuello-Servós, C., \& Nachar-Calderón, P. (2014) Evolución del comportamiento estratégico de las cooperativas versus empresas capitalistas: una aproximación descriptiva al efecto crisis. REVESCO. Revista de Estudios Cooperativos, Tercer Cuatrimestre, №116, pp. 77-102. DOI: http://dx.doi.org/10.5209/rev_REVE.2014.v116.45718.

Cuadrado-Serrán, M., \& Ciruela-Lorenzo, A.M. (2014) Las sociedades cooperativas y sociedades laborales como motor de desarrollo económico y social: Análisis de su impacto socioeconómico en la región de Andalucía. REVESCO. Revista de Estudios Cooperativos, Segundo Cuatrimestre, No 115 , pp.57-100. DOI: http://dx.doi.org/10.5209/rev_REVE.2014.v115.45278.

Cubedo Tortonda, M. (2006) Estudio económico-financiero de las empresas de Economía Social en España. Años 2000-2003. Observatorio Español de la Economía Social, Colección de Informes. Disponible en http://www.observatorioeconomiasocial.es/documentos/Serie_Informes_N1_Economico_Financiero.pdf?PHPSESSID=efab d72c4dc3d48869510703ad7e503c. 
Díaz-Foncea, M., \& Marcuello-Servós, C. (2010) Impacto económico de las cooperativas. La generación de empleo en las sociedades cooperativas y su relación con el PIB. CIRIEC-España, Revista de Economía Pública, Social y Cooperativa, $\mathrm{N}^{\mathrm{o}} 67$, pp. 23-44.

Esteban, M.L., Pérez, F.J. \& Gargallo, A. (2018) Rural areas and co-operatives: women's initiatives for development, REVESCO. Revista de Estudios Cooperativos, Primer Cuatrimestre, No127, pp.116-138. DOI:10.5209/REVE.58397.

Fernández, M.T., \& Márquez, M.A. (2009) Análisis de la capacidad competitiva relativa de las exportaciones intracomunitarias de productos agroalimentarios: el caso de la Unión Europea (UE-12). Información Comercial Española, Revista de Economía, № 851, pp. 135-156.

Fuentes-Saguar, P., \& Mainar-Causapé, A.J. (2015) Impacto económico y en el empleo de la Economía Social en España. Un análisis multisectorial. CIRIEC-España, Revista de Economía Pública, Social y Cooperativa, № 83, pp. 63-81.

Grávalos, M., \& Pomares, I. (2001) La adaptación de las sociedades laborales a la evolución del ciclo económico. Un estudio empírico para las diferentes comunidades autónomas. CIRIEC-España, Revista de Economía Pública, Social y Cooperativa, $\mathrm{N}^{\mathrm{o}} 38$, pp. 33-55.

Gutiérrez, A., Morán, J.C, Belda, J.I., Sánchez-Torné, I., \& Pérez-Suárez, M. (2014) Informe sobre la internacionalización de la Economía Andaluza y de sus provincias y el nuevo modelo productivo, 2. Patrocinado Fundación Cajasol y la Fundación de Investigación de la Universidad de Sevilla. Ed. Instituto de Estudios de Cajasol.

Martínez, M.Á., Sabín, F., Álvaro, A., Gallero, A., \& Salsón, S. (2019) La Economía Social y Solidaria: Balance provisional y perspectivas para España. Laboratorio de Alternativas, $\mathrm{N}^{\mathrm{o}}$ 2, pp. 1-26. Disponible en https://preview.tinyurl.com/y2nez7z6.

Mayor-Fernández, M., López-Menéndez, A. J., \& Pérez-Suárez, R. (2005) Escenarios de empleo regional. Una propuesta basada en análisis shift-share. Estudios de Economía Aplicada, № 23 (3), pp. 863-887.

Melián, A., \& Campos, V. (2010) Emprendedurismo y Economía Social como mecanismos de inserción sociolaboral en tiempos de crisis. REVESCO. Revista de Estudios Cooperativos, № 100, pp. 43-67.

Monzón, J. L., \& Chaves, R. (2017) Evolución reciente de la Economía Social en la Unión Europea. Edita: Comité Económico y Social Europeo. Disponible en https://preview.tinyurl.com/yysh7ztk.

Monzón, J.L., \& Chaves, R. (2012) La Economía Social en la Unión Europea. Informe elaborado para el Comité Social Europeo por el Centro Internacional de Investigación e Información sobre la Economía Pública, Social y Cooperativa (CIRIEC).

Pérez, B., \& Carrillo, E. (2000) Desarrollo local: Manual de Uso. ESIC Editorial.

Pérez, M. del C., \& Valiente, L. (2017) La localización sectorial del cooperativismo: una aproximación a nivel territorial español. REVESCO. Revista de Estudios Cooperativos, Nº123, pp.198-224. https://doi.org/10.5209/REVE.54916.

Pérez, M. del C., \& Valiente, L. (2019) Aproximación al perfil y calidad del empleo generado por las sociedades cooperativas andaluzas. REVESCO. Revista de Estudios Cooperativos, N130, pp.122-148. DOI: 10.5209/REVE.60989.

Ramos-Díaz, J. (2016) Green economy and employment: employment potential of the ecological transition in Spain. Cuadernos de Relaciones Laborales, № 2, pp. 433-453.

Rendón, L., Andrés, R., \& Mejía, P. (2019) Spatial Shift-share of municipal manufacturing employment. Metropolitan Areas: Mexico and Toluca Valley, 2008-2013. Economía, Sociedad y Territorio, N ${ }^{\circ} 19$ (59), pp. $1213-1242$. http://dx.doi.org/10.22136/est20191248.

Román-Cervantes, C. (2014) Las cooperativas españolas y los ciclos económicos. Un análisis comparado. CIRIECEspaña, Revista de Economía Pública, Social y Cooperativa, No 80, pp. 77-109.

Ruiz, J., Peña, A.R., \& Jiménez, M. (2014) Estudio de las exportaciones agroalimentarias españolas. Un análisis de competitividad a nivel regional. Colección Documentos de trabajo. $n^{\circ}$ 002/2014. Fundación Pública Andaluza Centro de Estudios Andaluces y Consejería de la Presidencia, Junta de Andalucía, Sevilla. Disponible en http://centrodeestudiosandaluces.info/PDFS/DT022014.pdf.

Sala-Ríos, M., Torres-Solé, T., \& Farré-Perdiguer, M. (2015) El empleo de las cooperativas. Un análisis comparativo de sus fases cíclicas y de su grado de sincronización. CIRIEC-España, Revista de Economía Pública, Social y Cooperativa, $\mathrm{N}^{\mathrm{o}} 83$, pp. 115-141.

Sanchis, J. R., \& Campos, V. (2005) Inserción sociolaboral, Economía Social y Desarrollo Local. Estudio empírico sobre la realidad actual del Agente de Empleo y Desarrollo Local en España. CIRIEC-España, Revista de Economía Pública, Social y Cooperativa, No 52, pp. 279-306.

Toia, P. (2013) Informe sobre la contribución de las cooperativas a la salida de la crisis. Disponible en https://preview.tinyurl.com/y6xyclnp.

Valiente Palma, L. (2019) ¿Podría estar contribuyendo el cooperativismo a fijar la población en el territorio de Andalucía? CIRIEC-España, Revista de Economía Pública, Social y Cooperativa, No 97, pp. 49-74. DOI: 10.7203/CIRIEC-E.97.13046. 